\title{
Effect of content and fineness of slag as high volume cement replacement on strength and durability of ultra-high performance mortar
}

\author{
Gupta S \\ National Institute of Technology, Jamshedpur, Jharkhand, India. \\ Corresponding Author: souradeepnus@gmail.com
}

Received : 30-08-2016

Revised: 15-10-2016

Accepted: 02-11-2016

\begin{abstract}
Replacement of cement by slag in ultrahigh performance concrete (UHPC) makes it a green material for building and construction application. However, slag hydrates slower which delay strength gain in UHPC which can be addressed by using slag of high fineness. In this study, cement is replaced by slag at $20 \%$ and $60 \%$ by weight. Slag of three different fineness is used$400 \pm 4 \mathrm{~m}^{2} / \mathrm{kg}, 556 \pm 5 \mathrm{~m}^{2} / \mathrm{kg}$ and $750 \pm 5 \mathrm{~m}^{2} / \mathrm{kg}$ at constant water-binder ratio of 0.25 for all mixes. Compressive and flexural strength were measured for mechanical performance while water penetration test and chloride migration test were conducted to enumerate durability.

Results show that early and late compressive strength and flexural strength is improved significantly by incorporation of slag with fineness $556 \pm 5 \mathrm{~m}^{2} / \mathrm{kg}$ compared to reference and slag of $400 \mathrm{~m}^{2} / \mathrm{kg}$ fineness. However, at similar fineness $20 \%$ slag incorporation is found to produce higher early strength compared to $60 \%$ slag although 90 day strength for both replacement percentages are similar. On durability aspects it is found that slag with fineness of $556 \mathrm{~m}^{2} / \mathrm{kg}$ and $750 \mathrm{~m}^{2} / \mathrm{kg}$ demonstrates significantly lower penetration depth and very high resistance to chloride migration at 28 day and 90 day age irrespective of slag replacement percentage. The study suggests that slag of high fineness (about $556 \mathrm{~m}^{2} / \mathrm{kg}$ based on the study) and $20-60 \%$ cement replacement can significantly accelerate hydration and improve long term durability of UHPC mortar.
\end{abstract}

Key words: Strength, Durability, Ultra high performance concrete, Chloride migration, Water penetration

\section{Introduction}

Ultra-high performance concrete (UHPC) is gaining popularity in building and infrastructure construction due to its fast strength development and superior mechanical and durability properties compared to conventional concrete (Pyo and El-Tawil,2015, Alkaysi et al.,2016). However, as every developed and developing economy is striving for sustainable construction and energy savings, the high energy consumption, material price and associated high $\mathrm{CO}_{2}$ emission for UHPC are restricting it from wide application in building and construction sector. To reduce cement content in UHPC, granulated blast furnace slag (GGBS) is commonly used to replace part of cement. It is well known that GGBS due to its hydraulic property reacts with water and form calcium silicate hydrate. However, although GGBS can be activated by calcium hydroxide and gypsum, the rate of hydration of GGBS in concrete is low (Regourd et al., 1983, Binici et al., 2007, Johari et al., 2011,Kim et al.,2016) which results in slower strength development of UHPC. Slower rate of strength development means that the designed strength would be achieved late which can delay removal of formwork and affect construction economy. Especially in applications at places of adverse conditions, for example, marine construction or underwater foundations, rapid strength gain is critical to durability and life of concrete construction. One of the ways to speed up hydration and strength development in UHPC containing slag is to modify the fineness of GGBS. GGBS of variable fineness will offer different surface area for hydration reaction and influence the distribution of hydration products in the cement matrix which can impact strength and durability of UHPC. Due to incorporation of fine slag particles, the rate of strength development of the concrete may be improved and the permeability of the concrete can be reduced due to reduced total pore volume, 
pore connection and the better filling of the pores in the interfacial transition zone (ITZ). It was reported that ultra fine GGBS-blended (UFGGBS) concrete showed reduction in creep value and drying shrinkage compared to OPC concrete (Li and Yao, 2001).The addition of UFGGBS results in a stronger structure and higher resistance to deformation caused by applied force (Teng et al., 2013). Moreover, the percentage of cement replacement by GGBS also influences strength development because of the difference in rate of hydration between cement and GGBS of normal fineness. Typically, minimum of $20 \%$ of cement replacement by GGBS is practiced in construction industry although several researches have tried high cement replacement, up to $60 \%$ to $80 \%$ (Yazici, 2007, Yazıcl et al., 2010). To boost up ongoing efforts to achieve sustainable construction, some green building codes and authorities including Building and Construction Authority of Singapore (BCA) have made provision for replacement of $20 \%$ cement by GGBS to prepare greener concrete which will cut down on the use of raw materials and emission (CP65, 2008).

The coupled effect of slag replacement and slag fineness on hardened properties of UHPC mortar is not widely studied. This study aims to explore the effect of content and fineness of slag on strength and durability of ultra-high performance concrete. To study the effect of slag fineness on mechanical strength and durability, mortar paste has been used in the study. GGBS of three different specific surface areas $-400 \mathrm{~m}^{2} / \mathrm{kg}, 556 \mathrm{~m}^{2} / \mathrm{kg}$ and $750 \mathrm{~m}^{2} / \mathrm{kg}$ is added at two different cement replacement percentages - $20 \%$ and $60 \%$ by weight. These two percentages of slag replacement are chosen to have significant difference in quantity of cement replacement in the mortar paste. It ensures that the difference in strength development and durability by incorporation of slag of different fineness in the UHPC mortar can be highlighted and studied. Compressive and flexural strength tests have been conducted to study the rate of strength development at different ages of UHPC while water penetration test and chloride migration test are conducted to estimate durability of UHPC with different slag fineness and content.

\section{Experimental program}

\subsection{Materials used}

Ordinary Portland cement (Type 1) conforming to specification of ASTM C150, 52.5N has been used in the study. The physical properties, chemical composition and mineralogical composition of the cement using Bogue calculation are mentioned in Table 1.

Table 1. Physical properties and chemical composition of OPC

\begin{tabular}{cc}
\hline Properties & Ordinary Portland cement used \\
\hline \hline \multicolumn{2}{c}{ Physical properties } \\
\hline Density $\left(\mathrm{kg} / \mathrm{m}^{3}\right)$ & 3180 \\
Blaine fineness $\left(\mathrm{m}^{2} / \mathrm{kg}\right)$ & 385 \\
Mean particle size $(\mu \mathrm{m})$ & 13.50 \\
\hline \multicolumn{2}{c}{ Chemical composition $(\%)$} \\
\hline $\mathrm{MgO}$ & 1.8 \\
$\mathrm{CaO}$ & 63.5 \\
$\mathrm{SO}_{3}$ & 2.1 \\
$\mathrm{Al}_{2} \mathrm{O}_{3}$ & 5.4 \\
$\mathrm{SiO}_{2}$ & 20.8 \\
$\mathrm{Na}_{2} \mathrm{O}$ & 0.59 \\
$\mathrm{Chloride}^{2}$ & 0.005 \\
\hline \multicolumn{2}{c}{ Mineralogical Composition $(\%)$} \\
$\mathrm{C}_{3} \mathrm{~S}$ & 58 \\
$\mathrm{C}_{2} \mathrm{~S}$ & 20 \\
$\mathrm{C}_{3} \mathrm{~A}$ & 2 \\
$\mathrm{C}_{4} \mathrm{AF}$ & 14 \\
\hline
\end{tabular}


The sand used is locally available river sand of fineness modulus of 2.54 and specific gravity of 2.65. The sand is dried in oven at $105{ }^{\circ} \mathrm{C}$ for 24 hours before sieving. Only particle sizes below $600 \mu \mathrm{m}$ is used in preparation of the mortar to allow better packing.

The composition of GGBS used is presented in Table 2. Fineness of GGBS was determined by Blaine permeability method. GGBS with three different fineness values were mixed $-400 \pm 4 \mathrm{~m}^{2} / \mathrm{kg}, 556 \pm$ $5 \mathrm{~m}^{2} / \mathrm{kg}$ and $750 \pm 5 \mathrm{~m}^{2} / \mathrm{kg}$ respectively with mean particle sizes of $4.09 \mu \mathrm{m}, 2.10 \mu \mathrm{m}$ and $1.45 \mu \mathrm{m}$ respectively.

\subsection{Mix design and mixing procedure}

The total cementitous content used in the study is $800 \mathrm{~kg} / \mathrm{m}^{3}$. The water to binder ratio (W:B) is maintained at 0.25 for all the mixes. As stated earlier, cement is replaced by $20 \%$ and $60 \%$ by weight of GGBS. For each replacement percentage, effect of three different GGBS fineness has been studied. A reference mortar (without GGBS) is prepared for comparison. The specimen terminologies are presented in Table 3.

Table 2. Chemical composition of blast furnace slag (GGBS) used in the study.

\begin{tabular}{cc}
\hline Chemical composition (\%) & GGBS (mass \%) \\
\hline \hline $\mathrm{SiO}_{2}$ & 39 \\
$\mathrm{Al}_{2} \mathrm{O}_{3}$ & 6 \\
$\mathrm{Fe}_{2} \mathrm{O}_{3}$ & 0.75 \\
$\mathrm{CaO}$ & 35 \\
$\mathrm{MgO}$ & 12 \\
$\mathrm{SO}_{3}$ & 1.10 \\
$\mathrm{~K}_{2} \mathrm{O}$ & 0.4 \\
\hline
\end{tabular}

Table 3. Mix design, description and terminologies

\begin{tabular}{|c|c|c|c|c|c|c|}
\hline $\begin{array}{c}\text { Mix } \\
\text { name }\end{array}$ & $\begin{array}{c}\text { Mix } \\
\text { code }\end{array}$ & $\begin{array}{l}\text { Cement } \\
\left(\mathrm{kg} / \mathrm{m}^{3}\right)\end{array}$ & $\begin{array}{c}\text { GGBS } \\
\left(\mathrm{kg} / \mathrm{m}^{3}\right)\end{array}$ & $\begin{array}{c}\text { Sand } \\
\left(\mathrm{kg} / \mathrm{m}^{3}\right)\end{array}$ & $\begin{array}{l}\text { Water-Binder } \\
\text { ratio }\end{array}$ & $\begin{array}{c}\text { Superplasticizer } \\
\left(\mathrm{kg} / \mathrm{m}^{3}\right)\end{array}$ \\
\hline $\begin{array}{c}\text { Reference } \\
20 \% \text { slag replacement }\end{array}$ & Ref & 800 & 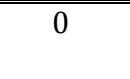 & 1400 & 0.25 & 6.95 \\
\hline $\begin{array}{c}\text { with GGBS fineness of } \\
400 \pm 4 \mathrm{~m}^{2} / \mathrm{kg}\end{array}$ & G20F400 & 640 & 160 & 1400 & 0.25 & 6.15 \\
\hline $\begin{array}{c}20 \% \text { slag replacement } \\
\text { with GGBS fineness of } \\
556 \pm 5 \mathrm{~m}^{2} / \mathrm{kg}\end{array}$ & G20F556 & 640 & 160 & 1400 & 0.25 & 5.90 \\
\hline $\begin{array}{c}20 \% \text { slag replacement } \\
\text { with GGBS fineness of } \\
750 \pm 5 \mathrm{~m}^{2} / \mathrm{kg}\end{array}$ & G20F750 & 640 & 160 & 1400 & 0.25 & 6.20 \\
\hline $\begin{array}{c}60 \% \text { slag replacement } \\
\text { with GGBS fineness of } \\
400 \pm 4 \mathrm{~m}^{2} / \mathrm{kg}\end{array}$ & G60F400 & 320 & 480 & 1400 & 0.25 & 5.95 \\
\hline $\begin{array}{c}60 \% \text { slag replacement } \\
\text { with GGBS fineness of } \\
556 \pm 5 \mathrm{~m}^{2} / \mathrm{kg}\end{array}$ & G60F556 & 320 & 480 & 1400 & 0.25 & 5.73 \\
\hline $\begin{array}{c}60 \% \text { slag replacement } \\
\text { with GGBS fineness of } \\
750 \pm 5 \mathrm{~m}^{2} / \mathrm{kg}\end{array}$ & G60F750 & 320 & 480 & 1400 & 0.25 & 6.05 \\
\hline
\end{tabular}

\subsubsection{Preparation and casting of specimen}

The mortar mixes have been prepared in a 60l Hobert mixer under the following steps: The first step of the mixing involves dry mixing of all the solid components which include cement, GGBS and sand. Mixing water is then added during 15-20 seconds and the mixing is continued for another 3 minutes at medium speed. Superplasticizer (ADVA $181 \mathrm{~N}$ manufactured by W.R.Grace) is then added 
to the mix and the composition was mixed for 1 minute before switching to high speed for next 1 minute. During mixing, the consistency of mixed mortar is checked by means of flow table test following ASTM C1437. All the mixes were prepared to achieve a uniform flow range between 150$160 \mathrm{~mm}$ and the superplasticizer dosage was adjusted accordingly which is presented in Table 3 for different mixes. After the flow test, the edges of the bowl are scraped the mixing was continued for 2 minutes. The mixture is finally mixed for three minutes at high speed. After mixing, the mortar was cast into respective mould placed on vibration table to achieve proper compaction.

The specimens for strength and durability testing are demolded after 22-24 hours and cured under $25 \pm 1^{\circ} \mathrm{C}$ and $95 \%$ relative humidity $(\mathrm{RH})$ till the age of testing. Compressive and flexural strength test of the mortars were carried out at age of 3 day, 7 day, 28 day and 90 day while water penetration test and chloride migration test were conducted at age of 28 day and 90 day.

\subsection{Tests methods}

\subsubsection{Flow table test}

The workability of mortar can be estimated from its flowability. Flow diameter was measured according to the procedure recommended by ASTM C1437. After 5 minutes of mixing some mortar was filled in truncated conical mould of $70 \mathrm{~mm}$ top diameter and $100 \mathrm{~mm}$ bottom diameter placed on flow table. Once the cone was filled, the top part was leveled. Then the mould was lifted and the mortar was allowed to flow. The subsequent diameter of the mortar is measured in two perpendicular directions and the average is reported as the final diameter.

\subsubsection{Compressive strength}

Compressive strength test has been performed on cube specimens. The results have been recorded by using a compression testing machine ((DMG Compression testing machine) operated at loading rate of $157 \mathrm{kN} / \mathrm{min}$. Before subjecting the specimens to test, the excess moisture is wiped off from the surface of the specimen.

\subsubsection{Flexural strength}

Flexural load is obtained by a three point loading on to a calibrated flexural testing frame (INSTRON) with displacement rate set at $0.50 \mathrm{~mm} / \mathrm{min}$. Specimen of dimension $40 \times 40 \times 160 \mathrm{~mm}$ is used. The distance between the supports in the frame is fixed at $100 \mathrm{~mm}$.

\subsubsection{Depth of water penetration}

Cylinder specimen $(100 \mathrm{~mm}(\mathrm{~d}) \mathrm{x} 200(\mathrm{~h}) \mathrm{mm}$ ) is used to measure depth of water penetration. After the curing period specimens have been allowed to dry in oven at $50{ }^{\circ} \mathrm{C}$ for 48 hours to ensure removal of moisture from pores of mortar. The surface of the specimens is then coated with epoxy to avoid any leakage from the sides during the test. The applied layer has been allowed to air dry for 24 hours before testing. Penetration testing has been conducted on a calibrated water penetration apparatus (CONTROLS water permeability apparatus). Water pressure of $6 \pm 0.5$ bar was applied for about 72 hours. After 72 hours the specimens were split into two halves and the maximum penetration depth (in $\mathrm{mm}$ ) has been recorded.

\subsubsection{Chloride migration coefficient}

Nord test Build 492 (Nord Test method, 1999) has been followed to determine chloride migration coefficient in the UHPC samples. Three $50 \mathrm{~mm}$ specimens have been tested for each mix at a time. The specimens were obtained by cutting cylinder specimens by high speed concrete cutter. The specimen was exposed to two solutions on both side - a $10 \%$ sodium chloride $(\mathrm{NaCl})$ solution on one side (cathode) and a $0.3 \mathrm{M}$ sodium hydroxide $(\mathrm{NaOH})$ solution on the other side (anode). Chloride ion was made to move into the specimen by application of an external potential across the 
specimen. After test duration the specimen was axially split across its circular cross section. The split surfaces were sprayed with $0.1 \mathrm{M}$ silver nitrate (AgNO3) solution to determine the chloride penetration by measuring the silver chloride precipitates formed. The chloride migration coefficient can be calculated according to the equations mentioned in Nord Test Build 492 (Nord Test method, 1999).

The test details are shown in Table 4.

Table 4. Test Details.

\begin{tabular}{cccc}
\hline $\begin{array}{c}\text { Curing } \\
\text { Regime }\end{array}$ & Type of specimen & Testing age(day) & Test conducted \\
\hline \hline Water & 100 mm cube & $3,7,28,90$ & Compressive strength \\
Water & $40 \times 40 \times 160 \mathrm{~mm}$ Prism & $3,7,28,90$ & Flexural strength \\
Water & $100(\mathrm{~d}) \times 200 \mathrm{~mm}(\mathrm{~h})$ & 28,90 & Water penetration test \\
Water & cylinder & 28,90 & Chloride migration test \\
\hline
\end{tabular}

\section{Results and discussion}

\subsection{Flowability of mortar}

It is observed from Table 3, that superplasticizer dosage is reduced with increased cement replacement by slag. Kim et al. (2016) reported similar findings that addition of slag as $50 \%$ cement replacement improved flowability by $34.4 \%$. Improvement in flow is due to reduction in water demand by slag particles compared to cement (Karri et al.,2015; Boukendakdji, 2009; Kourounis et al.,2007). The reduced water demand is due to lower rate of slag hydration attributed to its mineralogical composition. Cement replacement by slag also reduces the amount of ettringite produced during early stages of hydration which is responsible for improvement in flowability (Samet et al., 2004).

It is worth noting superplasticizer dosage is increased when slag of fineness $750 \mathrm{~m}^{2} / \mathrm{kg}$ is incorporated compared to that in case of slag of lower fineness values. Table 5 illustrates this finding.

Table 5. Reduction in superplasticizer (SP) dosage with increasing fineness and replacement rate of Slag.

\begin{tabular}{|c|c|c|c|}
\hline $\begin{array}{l}\text { Curing } \\
\text { Regime }\end{array}$ & Fineness(m2/kg) & $\begin{array}{c}\text { Reduction in SP dosage } \\
\text { compared to reference (\%) }\end{array}$ & $\begin{array}{c}\text { Difference in SP } \\
\text { dosage (\%) }\end{array}$ \\
\hline \multirow{3}{*}{$\begin{array}{l}20 \% \text { slag } \\
\text { replacement }\end{array}$} & G20F400 vs. Ref & 11.51 & - \\
\hline & G20F556 vs. G20F400 & 15.10 & 3.6 \\
\hline & G20F750 vs. G20F556 & 10.79 & $\begin{array}{c}-4.32 \text { (increased } \\
\text { demand) }\end{array}$ \\
\hline \multirow{3}{*}{$\begin{array}{l}60 \% \text { slag } \\
\text { replacement }\end{array}$} & G60F400 vs. Ref & 14.38 & - \\
\hline & G60F556 vs. G20F400 & 17.55 & 3.16 \\
\hline & G60F750 vs. G20F556 & 12.95 & $\begin{array}{c}-4.60(\text { increased } \\
\text { demand) }\end{array}$ \\
\hline
\end{tabular}

For example, in case of $20 \%$ replacement, while SP demand was reduced by $11.51 \%$ and $15.10 \%$ for slag fineness of $400 \mathrm{~m}^{2} / \mathrm{kg}$ and $556 \mathrm{~m}^{2} / \mathrm{kg}$ respectively compared to reference. However, for slag of fineness $750 \mathrm{~m}^{2} / \mathrm{kg}$, SP dosage was reduced by $10.79 \%$ meaning increase in SP demand by $4.32 \%$ compared to slag of $556 \mathrm{~m}^{2} / \mathrm{kg}$ fineness. Similarly trend can be observed in case of $60 \%$ slag replacement as well. This is attributed to increased interparticle friction when the density of fine particles increases around coarser cement and sand particles (RILEM report, 2000). The increased surface area due to ultra-fine slag particles increase the contact area of friction between other 
particles in the paste which offer resistance against flow resulting in reduction of flowability. Particle friction in powder materials is difficult to reduce by increasing interparticle distance through addition of more water, especially in case of high performance mortar. Thus to make up for water demand, higher amount of SP is needed to disperse the ultra-fine particles in the cement paste. However, one must be careful with increased demand for SP because high dosage may lead to segregation and bleeding.

\subsection{Compressive and flexural strength}

Development of compressive and flexural strength of slag containing specimen and reference specimen is presented in Fig. 1 and Fig. 2 respectively. It can be observed from the graphs that slag containing samples show higher compressive and flexural strength at 90 day than the reference (Ref) although slight reduction in early strength and 28 day strength takes place due to high volume slag replacement. Especially, mortar samples with slag of fineness $400 \mathrm{~m}^{2} / \mathrm{kg}$ show reduced 3 day, 7 day and 28 day strength irrespective of replacement percentage. It may be because of similar fineness of slag as that of cement $\left(385 \mathrm{~m}^{2} / \mathrm{kg}\right.$, from Table 1$)$.

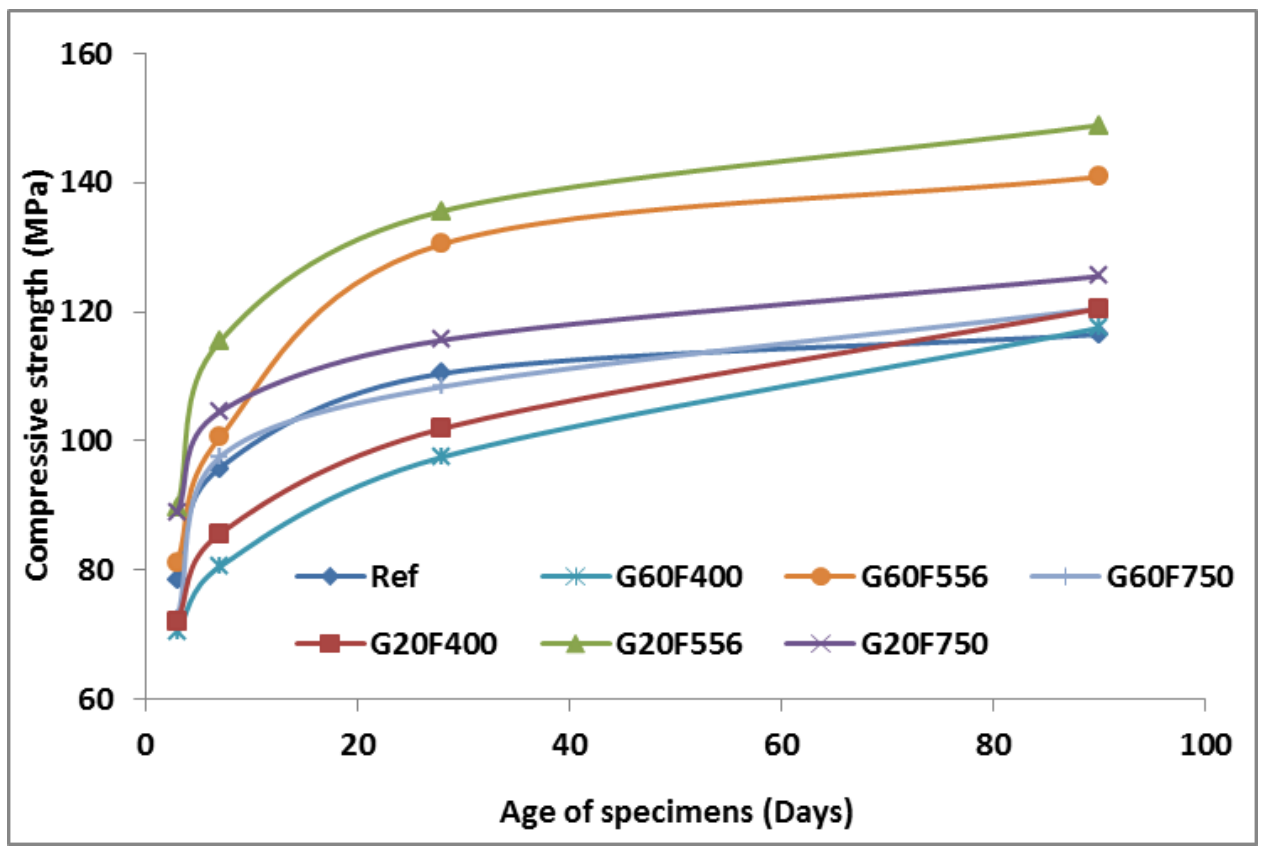

Fig 1. Development of Compressive strength

Strength development depends on packing density of mortar which also influence rate of hydration. Improved packing means that voids between cement particles should be filled by finer slag particles. However, packing density in the bulk cement paste is not significantly improved because slag of higher fineness $\left(400 \mathrm{~m}^{2} / \mathrm{kg}\right)$ compared to cement is used in this case as replacement. G20F556 mix achieved highest compressive and flexural strength at 7 day, 28 day and 90 day followed by G60F556. One can observe that when $60 \%$ of cement is replaced by GGBS, reduction of 3 day and 7 day strength takes place compared to reference and $20 \%$ replacement with same fineness. This can be attributed to slower hydration of slag and lesser rate of production of secondary calcium silicate hydrate.

Improvement in early compressive and flexural strength (3 day and 7 day) is observed when fineness of GGBS is increased to $556 \mathrm{~m}^{2} / \mathrm{kg}$. The percentage increase in early strength of $20 \%$ and $60 \%$ slag as cement replacement over reference mortar is reported in Table 6. 
Table 6. Percentage improvement in compressive and flexural strength with slag fineness of $556 \mathrm{~m}^{2} / \mathrm{kg} \mathrm{over}$ reference mortar

\begin{tabular}{|c|c|c|c|c|}
\hline & \multicolumn{2}{|c|}{$\begin{array}{c}\% \text { increase in compressive strength } \\
\text { over reference mortar(Ref) }\end{array}$} & \multicolumn{2}{|c|}{$\begin{array}{l}\text { \% increase in flexural strength over } \\
\text { reference mortar (Ref) }\end{array}$} \\
\hline & 3 day & 7 day & 3 day & 7 day \\
\hline G20F556 & 13.25 & 9.08 & 14.14 & 20.56 \\
\hline G60556 & 3.48 & 4.90 & 4.50 & 5 \\
\hline
\end{tabular}

Increase in fineness implies higher specific surface area of slag which allows faster hydration reaction. Moreover, finer slag particles can act as micro-filler between cement and sand particles and provide nucleation sites to boost up hydration. However, as fineness is further increased to $750 \mathrm{~m}^{2} / \mathrm{kg}$, both G20F750 and G60F750 batches show reduction in strength. 90 day strength in case of GGBS of fineness $750 \mathrm{~m}^{2} / \mathrm{kg}$ is almost similar to that of $400 \mathrm{~m}^{2} / \mathrm{kg}$ which implies that increase in fineness do not necessarily contribute to strength improvement.

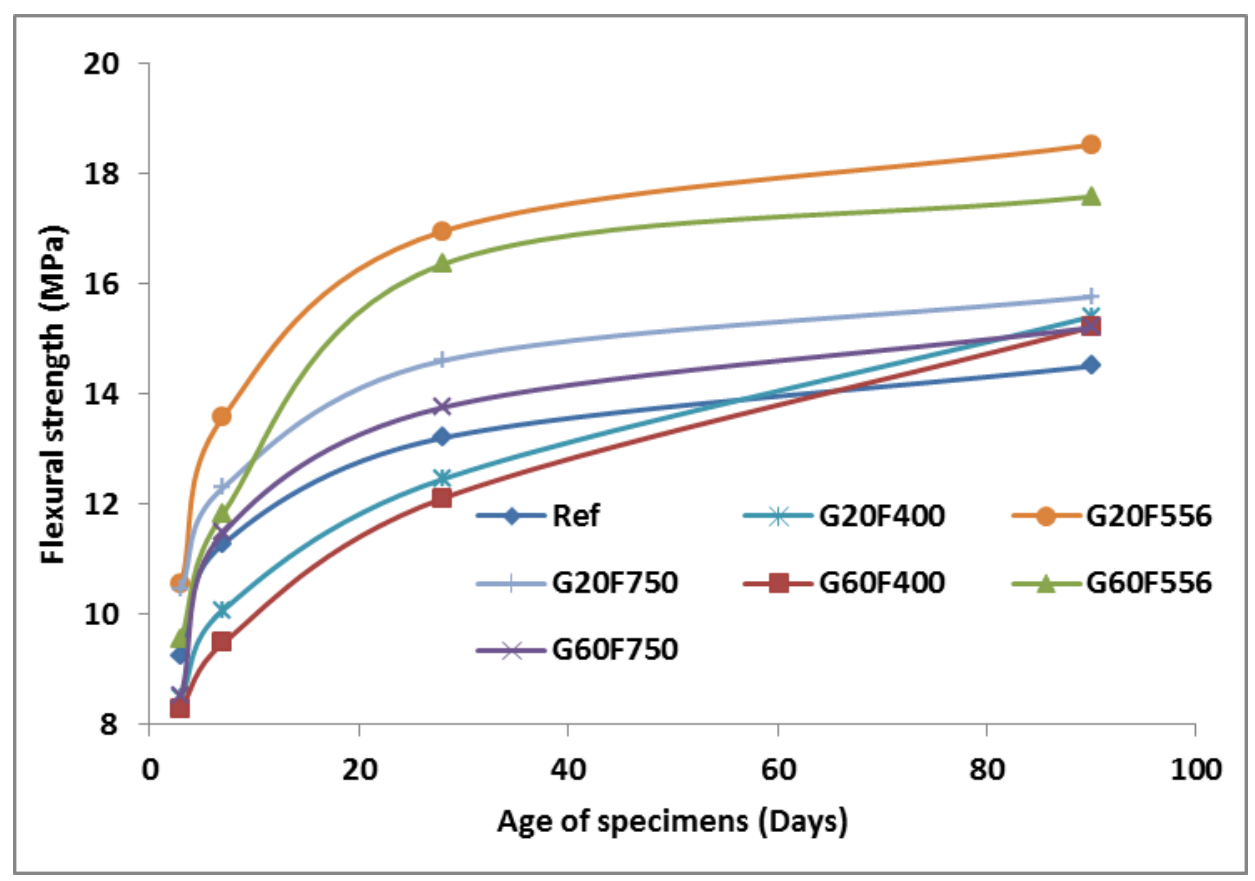

Fig 2. Development of flexural strength

28 day compressive strength is reduced by about $15 \%$ and $17 \%$ respectively for G20F750 and G60F750 than the maximum observed in each case which is for G20F556 and G60F556 respectively. Similarly, reduction in flexural strength by $15 \%$ and $16 \%$ is observed in G20F750 and G60F750 than the maximum.

Reduction in strength due to addition of ultrafine GGBS particles is believed to be due to intense cohesiveness developed from high fineness of GGBS which prevented it from bonding properly with the matrix. Ultrafine particles tend to have poor dispersion in the matrix due to physical Van Der Waal's force of attraction between the particles which results in formation of weak spots in the matrix by particle agglomeration. Particle agglomeration form localized voids in the paste. Therefore decrease in strength could be believed to have resulted from too many voids and interfacial bond failure within the matrix.

\subsection{Water penetration depth}

Depth of water penetration performed at 28 day and 90 day for reference and slag containing samples is reported in Fig.3. Samples containing 20\% and 60\% slag replacement show lower depth 
of penetration at 28 day and 90 day compared to reference. All types of GGBS used in the study has higher fineness compared to cement which means that finer slag particles could block some continuous pore network in the matrix resulting in reduction of penetration depth.

Comparing the effect of slag content on depth of penetration, one can observe that 28 day penetration of G20F400 is lower than that of G60F400 while there is no significant difference between penetration depths between G20F556 and G60F556, and G20F750 and G60F750. It may be explained by reduction in capillary channels by fine GGBS particles irrespective of slag replacement at 28 day. However, the 90 day results follow a different trend. Penetration depth in G20F556 and G20F750 is reduced by about $14 \%$ and $23.50 \%$ than G60F556 and G60F750 respectively.

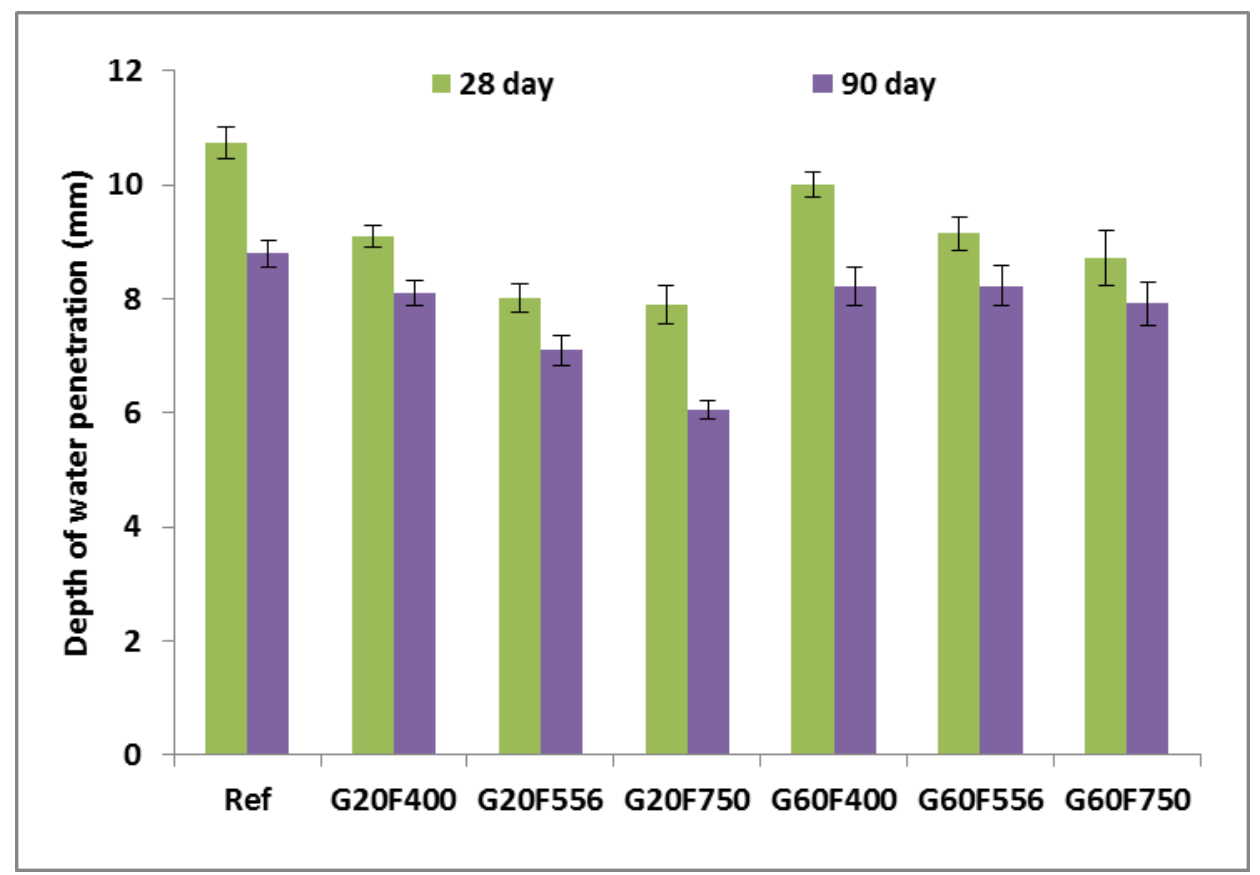

Fig 3. Depth of water penetration in reference and slag containing sample at different ages

Such observation may be attributed to coupled effect of hydration and pore-blocking by GGBS particles. Slag has a slower rate of hydration and therefore a minimum percentage of slag hydrates at 28 day which is more complete at 90 day. When introduced at $20 \%$ cement replacement, more complete hydration of slag occurs at 90 day. Physical densification of the microstructure takes place with the addition of fine GGBS and moreover, the pozzolanic reaction leads to the formation of secondary C-S-H. (Elahi et al., 2010). The secondary C-S-H formation results in reduction of capillary and gel porosity of the mortar which explains reduction in penetration depth of $20 \%$ replacement samples compared to that in case of $60 \%$ replacement. Influence of GGBS fineness on penetration depth in UHPC can be two fold- through reduction of open porosity and increasing precipitation of calcium-silicate hydrate which makes the matrix dense. This effect can be observed when $20 \%$ of cement is replaced by slag. Penetration depth at 28 day is reduced by about $18 \%$ in G20F556 compared to G20F400 although no further significant reduction took place in G20F750. Higher surface area facilitates faster hydration reaction and therefore penetration depth in G20F556 is reduced than G20F400 at 28 day. However, the same cannot be said for G20F750 because this mix showed reduction in 28 day strength (from Fig. 1). Therefore, it can be concluded that reduction of water penetration at 28 day in G20F750 and G60F750 is primarily due reduction in open porosity through better particle packing by finer slag particles. However, at 90 day age G20F750 shows highest resistance to water penetration probably due to formation of secondary hydration products by pozzolanic reaction of slag resulting in denser matrix. 


\subsection{Chloride Migration test}

Non-steady state chloride migration coefficient of UHPC mortar is computed based on NT BUILD 492 (Nord Test method, 1999) which is presented in Table8. Resistance of mortar against chloride penetration can be classified using the migration coefficient values (Nilsson et al., 1998) as shown in Table 7.

Table 7. Classification of chloride resistance based on 28 day resistivity (Nilsson, Ngo and Gjørv, 1998)

\begin{tabular}{cc}
\hline $\begin{array}{c}\text { Chloride migration } \\
\left.\text { coefficient (Dx10-12 } \mathrm{m}^{2} / \mathrm{s}\right)\end{array}$ & $\begin{array}{c}\text { Classification of resistance to } \\
\text { chloride penetration }\end{array}$ \\
\hline \hline 15 & Low \\
$10-15$ & Moderate \\
$5-10$ & High \\
$2.5-5$ & Very high \\
$<2.5$ & Extremely high \\
\hline
\end{tabular}

All the mixes incorporating slag show reduction in chloride migration coefficient than the reference mortar at 28 day and 90 day age. The results show that as the fineness of slag increases there the migration coefficient is reduced. At 28 day and 90 day chloride migration coefficient of G20F556 is reduced by about $59 \%$ and $82 \%$ respectively compared to G20F400 although further increase in slag fineness do not show significant improvement. Similar trend is observed in case of G60F556 which shows reduction in chloride migration coefficient by about $58 \%$ and $72 \%$ compared to G60F400 at 28 day and 90 day respectively.

Based on Table 6 classification, resistance of G20F556, G20F750, G60F556 and G60F750 at 28 day and 90 day can be classified as very high and extremely high respectively. Therefore, it can be concluded that incorporation of fine slag (minimum fineness $556 \mathrm{~m}^{2} / \mathrm{kg}$ based on this study) reduces pore connectivity and blocks migration of chloride ion into mortar. It is also worth noting that chloride migration coefficient significantly reduces beyond the curing age of 28 day although development of compressive and flexural strength slows down which is also supported by Teng et al. (2013). It may be due to deposition of secondary hydration products at localized zones around the slag particles due to pozzolanic reaction which breaks the continuity of pore network.

Table 8. Computed chloride migration coefficient from rapid chloride migration test

\begin{tabular}{ccc}
\hline Samples & Age(day) & Chloride migration coefficient $\left(\mathrm{Dx} 10^{-12} \mathrm{~m}^{2} / \mathrm{s}\right)$ \\
\hline \hline \multirow{2}{*}{ Ref } & 28 & 13.61 \\
& 90 & 11.48 \\
\multirow{2}{*}{ G20F400 } & 28 & 10.14 \\
& 90 & 7.30 \\
\hline \multirow{2}{*}{ G20F556 } & 28 & 4.14 \\
& 90 & 1.21 \\
\hline \multirow{2}{*}{ G20F750 } & 28 & 4.18 \\
& 90 & 1.25 \\
\multirow{2}{*}{ G60F400 } & 28 & 10.10 \\
& 90 & 8.21 \\
\hline \multirow{2}{*}{ G60F556 } & 28 & 4.21 \\
& 90 & 2.25 \\
\multirow{2}{*}{ G60F750 } & 28 & 4.37 \\
& 90 & 2.43 \\
\hline
\end{tabular}




\subsection{Comparison of mechanical and durability properties of mortar with respect to replacement rate and fineness of slag}

Fig.4 presents the strength and durability properties at 28 day of ultrahigh performance mortar with respect to different fineness values of slag and cement replacement rates. While compressive strength is plotted on primary vertical axis, flexural strength, depth of penetration and chloride diffusivity are plotted on secondary vertical axes (right y-axis).

It can be observed from Fig.4 that G20F556 offers the highest 28 day strength although depth of water penetration and chloride diffusivity are similar to that of G20F750. It has earlier been discussed that while strength development is related to microstructure of mortar paste, transport properties are more sensitive to pore connectivity of the matrix (Wang et al., 2014).

Strength is influenced by the composition and the microstructure of the specimen. Several factors including water to cement ratio, aggregates grading, age and curing condition, admixtures, can influence strength because they will influence the hydration degree and microstructure of the specimen. Higher hydration means filling up of pore spaces by solid hydration products resulting in increase in strength.

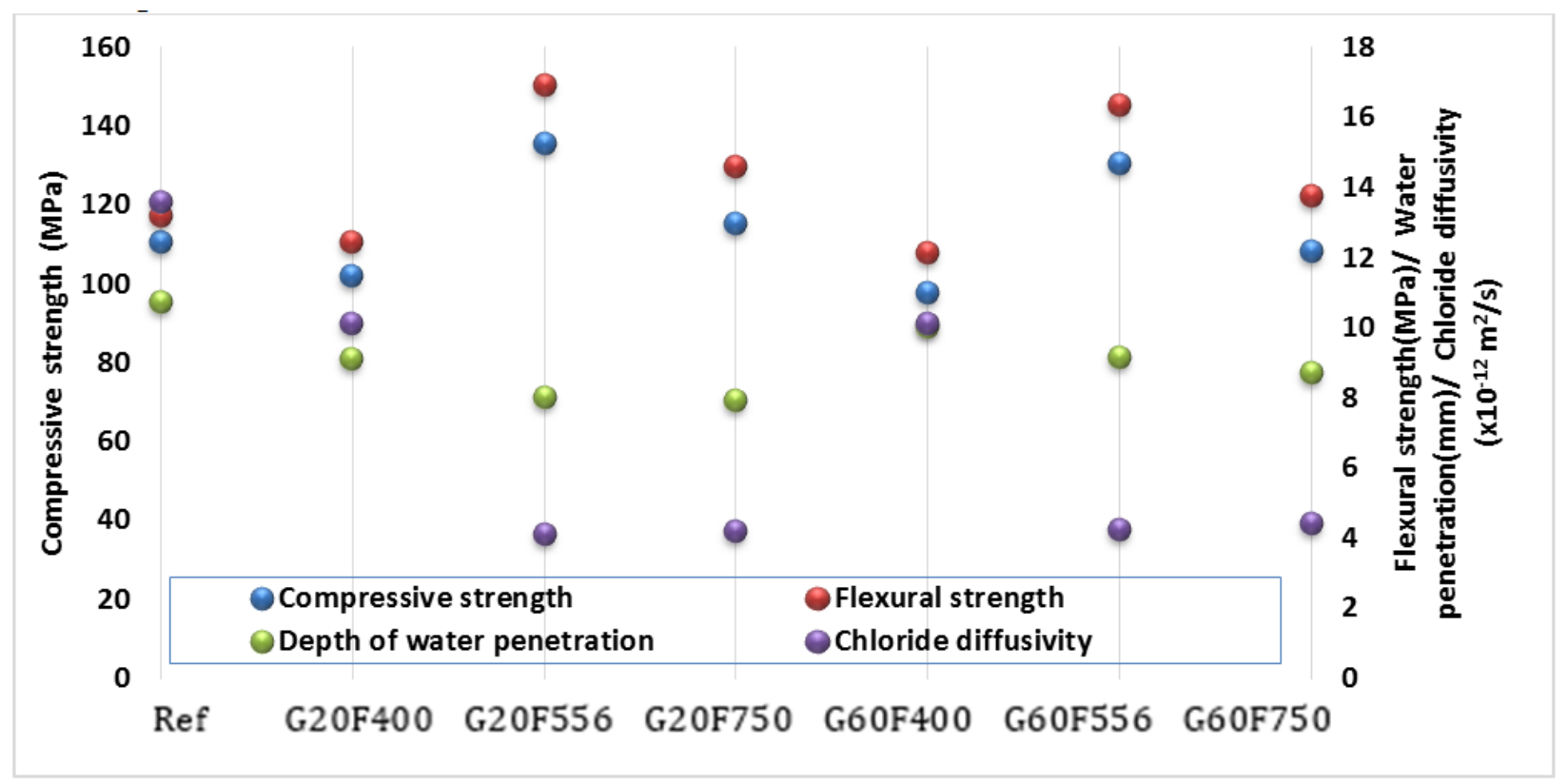

Fig 4. Comparison of properties of ultrahigh performance mortar at 28 day with respect to cement replacement rate and fineness of slag

Therefore, microstructure of mortar is the main factor influencing strength. In this study, for a particular cement replacement rate, all the specimens were made with the same cement, sand and water, using the same $\mathrm{w} / \mathrm{c}$ ratio and sand to cement ratio. The only difference was addition of slag of variable fineness. Therefore, it may be implied that slag of higher fineness is beneficial for improving transport properties of ultrahigh performance mortar while slag of $400 \mathrm{~m}^{2} / \mathrm{kg}$ fineness performs best from the perspective of strength development at both $20 \%$ and $60 \%$ cement replacement rate.

Comparing the effect of replacement rate on strength and durability properties, one can observe that the strength development is lower in case of $60 \%$ replacement. However, the difference between penetration depth and chloride diffusivity is not as significant as difference between strength development at both replacement rates. Such observation results due to introduction of fine slag particles which will reduce porosity of mortar regardless of rate of strength gain. Therefore, from the results it can be implied that $60 \%$ replacement of cement by slag is feasible 
where faster strength development is not a stringent requirement, which will be more economic and sustainable from the perspective of reduction in associated carbon emission.

\section{Conclusion}

Based on the outcome of the study, the following conclusions can be drawn:

a) Although water demand is reduced with increase in cement replacement percentage, slag of higher fineness tends to increase water demand because of more interparticle friction around cement grains and sand particles.

b) Deployment of slag with higher fineness, about $556 \mathrm{~m}^{2} / \mathrm{kg}$, significantly improves early strength and 28 day strength of UHPC mortar when added to replace $20 \%$ and $60 \%$ of cement. However, the effect on early strength diminishes when slag of very high fineness, about $750 \mathrm{~m}^{2} / \mathrm{kg}$ is used although 90 day strength is similar to that of reference mortar.

c) Depth of water penetration is significantly reduced with increase in slag fineness up to 750 $\mathrm{m}^{2} / \mathrm{kg}$. Unlike mechanical strength, resistance of water penetration is found to be directly proportional to fineness of slag due to ability of fine particles to reduce porosity of matrix. Lowest penetration depth at 28 day and 90 day is observed in case of $20 \%$ cement replacement of slag fineness $750 \mathrm{~m}^{2} / \mathrm{kg}$.

d) UHPC mortar with slag of fineness $556 \mathrm{~m}^{2} / \mathrm{kg}$ irrespective of replacement percentage showed very high and extremely high resistance to chloride migration at 28 day and 90 day. Unlike mechanical strength, resistance to chloride migration is observed to be significantly affected by age beyond 28 day, increasing from 28 day to 90 day age of specimen.

e) It can be concluded from this study that about $20 \%$ slag replacement with high fineness, about $556 \mathrm{~m}^{2} / \mathrm{kg}$ may be optimal to develop early strength and improve long term mechanical and durability performance. From the results, it can be justified the application of UHPC with $20 \%$ cement replacement by slag of high fineness can be an ideal material for construction and repair under adverse conditions and short turn-around time.

\section{References}

Alkaysi, M., El-Tawil, S., Liu, Z., and Hansen, W. (2016). Effects of silica powder and cement type on durability of ultra-high performance concrete (UHPC). Cem. Concr. Compos., 66, 47-56.

ASTM (2007). Standard Test Method for Flow of Hydraulic Cement Mortar, Standard Specification C1437-07, ASTM, West Conshohocken, Pennsylvania.

ASTM (2016e1). Standard Specification for Portland Cement, Standard Specification C150/150M, ASTM, West Conshohocken, Pennsylvania.

Binici, H., Temiz, H., and Köse, M. M. (2007). The effect of fineness on the properties of the blended cements incorporating ground granulated blast furnace slag and ground basaltic pumice. Construction and Building Materials, 21(5), 1122-1128.

Boukendakdji, O., Kenai, S., Kadri, E., and Rouis, F. (2009). Effect of slag on the rheology of fresh selfcompacted concrete. Construction and Building Materials, 23(7), 2593-2598.

CP65(2008). Design guide of high strength concrete. Building and Construction Authority (BCA) Sustainable construction series 3 .

Elahi, A., Basheer, P., Nanukuttan, S., and Khan, Q. (2010). Mechanical and durability properties of high performance concretes containing supplementary cementitious materials. Construction and Building Materials, 24(3), 292-299.

Johari, M. M., Brooks, J., Kabir, S., and Rivard, P. (2011). Influence of supplementary cementitious materials on engineering properties of high strength concrete. Construction and Building Materials, 25(5), 26392648. 
Karri, S. K., Rao, G. R., and Raju, P. M. (2015). Strength and Durability Studies on GGBS Concrete. SSRG International Journal of Civil Engineering (SSRG-IJCE), 2(10),34-41.

Kim, H., Koh, T., and Pyo, S. (2016). Enhancing flowability and sustainability of ultra high performance concrete incorporating high replacement levels of industrial slags. Construction and Building Materials, $123,153-160$.

Kourounis, S., Tsivilis, S., Tsakiridis, P., Papadimitriou, G., and Tsibouki, Z. (2007). Properties and hydration of blended cements with steelmaking slag. Cem. Concr. Res., 37(6), 815-822.

Li, J., and Yao, Y. (2001). A study on creep and drying shrinkage of high performance concrete. Cem. Concr. Res., 31(8), 1203-1206.

Nilsson, L., Ngo, M., and Gjørv, O(1998). High-performance repair materials for concrete structures in the port of Gothenburg. Proc., Second international conference on concrete under severe conditions: environment and loading, 1193-1198.

NT BUILD 492 (1999). Concrete, mortar and cement-based repair materials: chloride migration coefficient from non-steady-state migration experiments. Nordtest Method.

Pyo, S., and El-Tawil, S. (2015). Capturing the strain hardening and softening responses of cementitious composites subjected to impact loading. Construction and Building Materials, 81, 276-283

Regourd, M., Thomassin, J., Baillif, P., and Touray, J. (1983). Blast-furnace slag hydration. Surface analysis. Cem. Concr. Res., 13(4), 549-556.

RILEM (2000).Self-Compacting Concrete. State-of-the-art report. RILEM report, 23(2000), 150.

Samet, B., and Chaabouni, M. (2004). Characterization of the Tunisian blast-furnace slag and its application in the formulation of a cement. Cem. Concr. Res., 34(7), 1153-1159.

Teng, S., Lim, T. Y. D., and Divsholi, B. S. (2013). Durability and mechanical properties of high strength concrete incorporating ultra fine ground granulated blast-furnace slag. Construction and Building Materials, 40, 875-881.

Wang, J., Soens, H., Verstraete, W., and De Belie N.(2014).Self-healing concrete by use of microencapsulated bacterial spores. Cem. Concr. Res., 56(1), 39-52.

Yazici, H. (2007). The effect of curing conditions on compressive strength of ultra high strength concrete with high volume mineral admixtures. Building and environment, 42(5), 2083-2089.

Yazıcı, H., Yardımcı, M. Y., Yiğiter, H., Aydın, S., and Türkel, S. (2010). Mechanical properties of reactive powder concrete containing high volumes of ground granulated blast furnace slag. Cem. Concr. Compos., 32(8), 639-648. 